\title{
Isolation and Application of the Lemongrass Essential Oil of Cymbopogon Nardus L.as a Growth Inhibitor of Lichens on Stone Cultural Heritage
}

\author{
Riyanto $^{1 *}$, Dyah Tri Untari ${ }^{2}$ and Nahar Cahyandaru ${ }^{3}$ \\ ${ }^{1,2}$ Department of Chemistry, Islamic University of Indonesia, Jl. Kaliurang KM 14,5 Sleman Yogyakarta \\ Indonesia 55584 \\ ${ }^{3}$ Borobudur Conservation Office, Borobudur, Magelang, Central Java, Indonesia.
}

\begin{abstract}
Isolation and application of the lemongrass essential oil Cymbopogon Nardus L. as at growth inhibitor of lichens on stone cultural heritage has been done. The lemongrass essential oil Cymbopogon nardus $L$ was resulted using water distillations. The lemongrass essential oil Cymbopogon Nardus $L$ used in this research was analyzing the physic characteristic, i.e. density, refractive index, and heavy metal content of $P b$, $\mathrm{Cd}$, and $\mathrm{Cr}$ using the atomic absorption spectrophotometer and the chemical component using Gas Chromatography Mass Spectroscopy. The result indicated that physical characteristic of essential oil have refractive index and density are 1.469 and $0.8846 \mathrm{gr} / \mathrm{mL}$, respectively. The analysis of $\mathrm{Pb}$ and $\mathrm{Cd}$ indicated were not detected, and Cr heavy metal is $6.093 \mathrm{mg} / \mathrm{kg}$. The chemical component analysis indicated the existence of 20 compound components which had five main components, i.e. Citronella $47.30 \%$, $\beta$-citronellol $16.05 \%$, Trans-Geraniol 12.98\%, Lynalil Acetate 4.91\%, and Trans-Caryophyllene 4.70\%. The lemongrass essential oil Cymbopogon nardus $L$ was applied into some stone cultural heritages which had concentration variations as follows: 1, 5, 10, 15, 20 and 25\%. The antifungal activity which were resulted from lichens isolation process indicated a prevention of fungi growth. The results from this research show diametrical zone of oil concentrations of $1 ; 5 ; 10 ; 15 ; 20 ; 25$, which were as much as $0 ; 6 ; 12 ; 18 ; 29$ and $33 \mathrm{~mm}$, respectively. As a conclusions is the higher concentration of lemongrass essential oil Cymbopogon nardus $L$ were more effective to inhibit the growth of fungi on lichens.
\end{abstract}

Keywords: Cymbopogon nardus L, lichens, stone, cultural, heritage

\section{Introduction}

Cultural heritage objects made of wood, stone, cloth and paper. Objects of cultural heritage should be protected from extinction and damage caused by natural processes such as acid rain, insects and microbial attack. Types of microbes that grow on rocks that mushroom crust (Lichens). The microbes can be easily grown on rocks, sandstone, limestone and gypsum [1]. The epiphytes on stone can provide protection on the stone material, but this approach to stones and some cases it does not apply to stone heritage [2]. Many types of cleaning what remove these organisms on the surface of stone have been developed, ranging from dry methods (using brushes), going through the use of chemical agents, steam, high water pressure up to the recently method of dry ice blasting [3].

Borobudur temple site made of andesite have various problems related with damages such as degradation by the influence of chemicals, as well as biological organisms. Many factors that cause damage to the historic building are chemical, physics and microbiology plays an important role in this process [4]. Microbial colonization of stones depends on environmental factors such as water availability, $\mathrm{pH}$, climatic exposure, nutrient sources, and petrologic parameters, such as mineral composition, type of cement as well as porosity and permeability of the rock material [5]. Biotic damage is caused by growth and activity of high-level bodies in the form of plants, animals and microorganism. Body's activity due to growth and metabolism can be accelerated physical and chemical environmental conditions which favor. Damages is getting worse because of the rock temple is an outdoor building so that it can be damaged due to physical factors (mechanical), chemistry and biology that can stand alone or a combination of more than one factor. The process of growth and metabolism of organisms require water, high relative humidity, nutrients, and to require the bodies of photosynthetic light [4].

Same researcher report that the actions of lichens and confirmed that lichens have physical and chemical effects. Mechanical damage caused by the penetration of hyphae into the rock and the expansion and shrinkage of the thallus (vegetative part of the fungi) under changes in humidity. Chemical Damages, however, is more important and can occur in three ways: by their secretion of oxalic acid, the formation of carbonic acid, and the formation of other acids capable of forming ions such as calcium chelate [6-7].

The damage to stone cultural heritage objects caused by lichens requires cleanup efforts. cleaning 
process use of pesticides, fungicides and insecticides synthetic such as AC 322 for cleaning lichens is not considered, because these materials contain the hazardous and toxic materials, especially the content of Arcopal at AC 322 which is hazardous and toxic materials that causing danger to humans who undertake conservation efforts, visitors, and the environment around cultural heritage objects. These materials can cause cancer because it is carcinogenic and mutagenic.

Alternative materials for the conservation of cultural heritage object using natural pesticides or vegetable has the potential to be developed. Botanical pesticides are pesticides that can be an alternative to reduce the use of synthetic pesticides. One of the natural materials that are easily obtainable, low cost and high effectiveness are essential oils. Some essential oils contain compounds benzene and the OH group, so that it can act as a botanical pesticide. Essential oil-based pesticide registration has escaped from the EPA (Environmental Protection Agency) and declared safe from the GRAS (Generally Recognized as Safe) so friendly to humans and the environment [8]. Same researcher report that the effect of essential oil to antifungal activity and bio pesticide [9-12].

This paper report that the isolation and application of lemongrass essential oil Cymbopogon Nardus L. as at growth inhibitor of lichens on stone cultural heritage. Isolation of lemongrass essential oil Cymbopogon Nardus L has been done using steam distillation. Physical and chemical characterization of lemongrass essential oil Cymbopogon Nardus L has been done using Atomic Absorption Spectrophotometer (AAS) and Gas Chromatography-Mass Spectrometry (GC-MS). The effect of lemongrass essential oil concentration to growth inhibitor of lichens has been done using diameter inhibition zone parameter and Scanning Electron Microscope (SEM).

\section{Experiments}

\subsection{Preparation of Lemongrass Essential Oil of Cymbopogon nardus $L$}

Lemongrass essential oil samples taken from the manufacturing plant essential oils Center of Essential Oil Studies (CEOS), Yogyakarta, Indonesia, generated from oil refining process which uses a system of steam distillation, steam distillation apparatus made of stainless steel with a capacity of $10 \mathrm{~kg}$ of raw material. Lemongrass samples used for isolation is a sample of the type Cymbopogon nardus L.as that has been dried, molt, and fell from the clove tree. The content of essential oil was analyzed by GC-MS Shimadzu QP 2010. Columns and detectors are used according to the essential oil of lemongrass. Analysis of heavy metals contained in the volatile oil consisting of $\mathrm{Cr}, \mathrm{Cd}$ and $\mathrm{Pb}$ has been done by using Atomic Absorption Spectrophotometer (AAS) Perkin Elmer 5500.

\subsection{Isolation of fungi of lichens and colony selection}

Fresh lichens scraped from the stone temples. All equipment such as scarpered, petri dish should be in a state of sterile to avoid contaminants that interfere observations of other microorganisms. Lichens which have been scraped then inserted uniformly into three sterile petri dish and cultured in a medium PDA using poured method, allowed for 27-48 days to grow colonies. After colonies formed in third petri dished method, then selected a type of fungi that grows predominantly on third petri dish method then chosen as the fungi of lichens. The fungi culture was inoculated into a new PDA and inoculated on an agar medium slant for the purposes of the stock. Types of fungi were identified using a microscope.

\subsection{Testing Antifungal Activity of Lemongrass Essential Oils diffusion method}

Paper disk diameter of $6 \mathrm{~mm}$ dipped on the test solution which concentration of $1 \%, 5 \%, 10 \%, 15 \%$, and $25 \%$, then taken cultured lichen fungi using aseptic way and put in a sterile petri dish, then poured PDA medium and twisted around to flatten culturing the fungi in a petri dish. After becoming semi-solid medium, paper aseptically placed on a layer of agar, sought to put the filter paper in the middle of the circle petri dish and then incubated at room temperature to form a fungi colony. Inhibitory zone was observed and measured to the nearest $0.5 \mathrm{~mm}$ with a ruler. Determination of the effectiveness of the inhibition zones of the five variants of concentration and made optimum concentration.

\subsection{Testing Inhibition Effects of Lemongrass Essential Oils to the surface of stone heritage}

Applied test solution concentration of $1 \%, 5 \%, 10 \%, 15 \%$, and $25 \%$, to the surface of the lichen on the stone of cultural heritage. Observations were made 24 hours after application of the oil, and observed for 5 days after the application of essential oils. Observations were made in two ways are visually by observing the change in color of the surface of the lichens are applied, where the color change compared with the observation of discoloration on the control and using Scanning Electron Microscope (SEM) JEOL JSM-IT300. 


\section{Result And Discussion}

\subsection{Identification of the Lemongrass Essential Oil of Cymbopogon nardus $L$}

Fig. 1 shown chromatogram the result of the analysis of chemical components contained in the lemongrass essential oil of Cymbopogon nardus L. using GC-MS. A GC-MS instrument GC-MS Shimadzu QP 2010 equipped was used to study the composition of the lemongrass essential oil to analyze its quality. Temperature-programming of the oven included an initial hold at $50^{\circ} \mathrm{C}$ for $5 \mathrm{~min}$ and a rise to $240^{\circ} \mathrm{C}$ at $3^{\circ} \mathrm{C} / \mathrm{min}$ followed by additional rise to $60-300^{\circ} \mathrm{C}$ at $10^{\circ} \mathrm{C} / \mathrm{min}$. The detector, interface and injector were set at 250.3 , 300.1 and $250^{\circ} \mathrm{C}$, respectively. Carrier gas, He, was adjusted to a linear velocity of $81.5 \mathrm{~mL} / \mathrm{min}$. The compounds were identified by matching their mass spectral fragmentation patterns with those stored in the spectrometer database, using the National Institute of Standards and Technology Mass Spectral database. Refractive indices $\left(20^{\circ} \mathrm{C}\right)$ of oil were found is 1.469 . The refractive index values indicated that the components were as monoterpene, sesquiterpene and their derivatives. The values of the oil specific gravity ranged from $0.8846 \mathrm{~g} / \mathrm{cm}^{3}$.

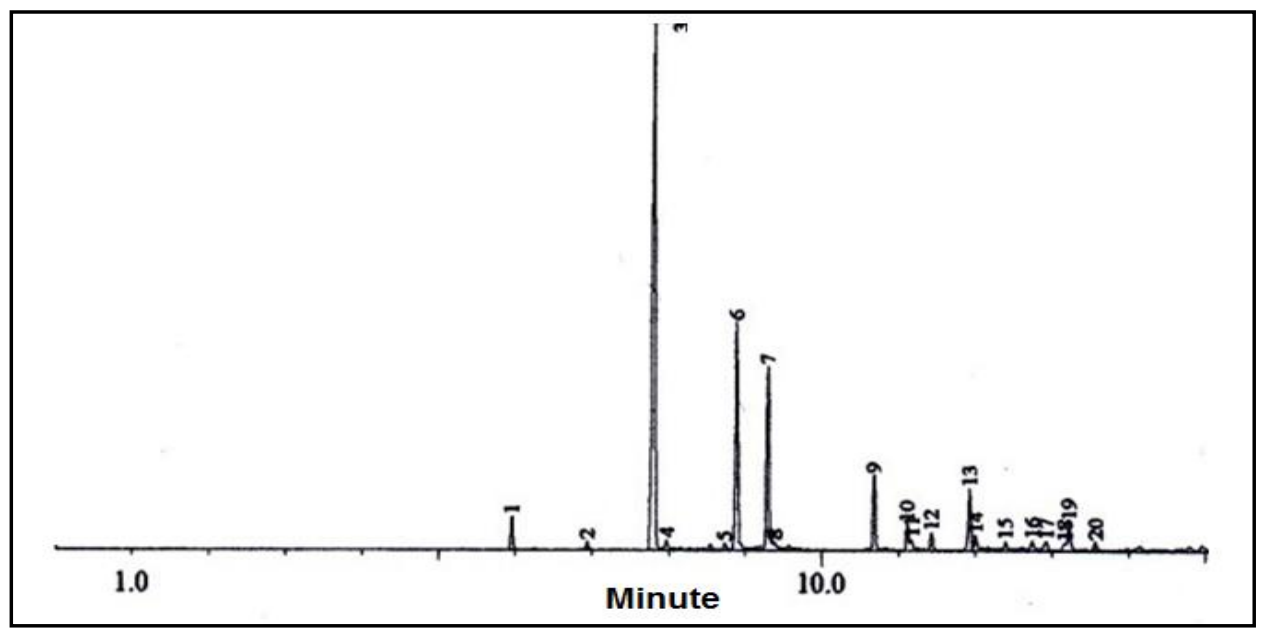

Figure 1 Chromatogram result analysis from lemongrass essential oil Cymbopogon nardus L.

Table 1 Percentage of compounds in the lemongrass essential oil of Cymbopogon nardus $L$ as identified by GCMS analysis

\begin{tabular}{|l|l|l|l|}
\hline No. & RT & Compounds & \% Peak area \\
\hline 1 & 5.950 & 1-Limonene & 2.04 \\
\hline 2 & 6.942 & Linalool & 0.48 \\
\hline 3 & 7.809 & Citronelle & 47.30 \\
\hline 4 & 7.967 & Neoiso Isopulegol & 0.70 \\
\hline 5 & 8.733 & 1,3-Dioxane, 5-ethenylidene-2,2-dimethyl & 0.35 \\
\hline 6 & 8.889 & Beta-citronellal & 16.05 \\
\hline 7 & 9.300 & Trans-Geranial & 12.98 \\
\hline 8 & 9.383 & 2L,4D-Dihydroxyeicosane & 0.53 \\
\hline 9 & 10.680 & Citronellyl acetate & 4.91 \\
\hline 10 & 11.117 & Linalyl acetate & 1.76 \\
\hline 11 & 11.167 & (+)-Cycloisosativene & 0.71 \\
\hline 12 & 11.425 & (-)-beta-Elemene & 1.23 \\
\hline 13 & 11.925 & Trans-Caryophyllene & 4.70 \\
\hline 14 & 12.000 & Alpha-Bergamotene & 0.96 \\
\hline 15 & 12.392 & Alpha-Humulene & 0.54 \\
\hline 16 & 12.742 & Germacrene-D & 0.59 \\
\hline 17 & 12.925 & Alpha-Muurolene & 0.76 \\
\hline 18 & 13.167 & Gamma.-Muurolene & 0.64 \\
\hline 19 & 13.225 & Delta-Cadinene & 2.15 \\
\hline 20 & 13.567 & Elemol & 0.60 \\
\hline
\end{tabular}

Table 1 show the GC-MS chromatograms of the lemongrass essential oil of Cymbopogon nardus $L$ the presence of several components that were identified and compared with the fragmentation patterns using the mass spectral data base of the gas chromatograph computer. The essential oil of Cymbopogon nardus $L$ analyzed in this study was dominated by a high percentage of citronelle (47.30\%), beta-citronellal (16.05\%), transgeranial $(12.98 \%)$, citronellyl acetate $(4.91 \%)$, trans-caryophyllene $(4.70 \%)$ and delta-cadinene $(2.15 \%)$. Based on atomic absorption spectrophotometer (AAS) analysis of the essential oil of Cymbopogon nardus $L$ to $\mathrm{Pb}$ and $\mathrm{Cd}$ are not detection. Determination of Cr total in the essential oil of Cymbopogon nardus $L$ is $6.093 \mathrm{mg} / \mathrm{kg}$. 


\subsection{Identification of fungi in Lichens on Stone Cultural Heritage}

When choosing the restoration material, the types of epiphytes have to be considered. The lichens consist of an epithelial layer; an algal layer, a medulla (fungal layer) and a lower cortex [3]. Fig. 2 shows observations of fungi in lichens using a microscope with a magnification of $400 \mathrm{X}$. Fig. 2A show pencillium sp fungi observations that live single. Fig. 2B show fungi that live in colonies and Fig. $2 \mathrm{C}$ show sectional fungi Penicillium sp. Isolation and identification of fungi in lichens has been done using potatoes dextrose agar (PDA), which is a selective medium for growing fungi. Identification of fungi has been done after the fungal colonies formed and was observed using a microscope. Penicillium sp is a genus of fungi of the order hypomicetes, phylum ascomycota. Penicilium sp has a characteristic hyphae form spore's entity called conidia. Conidia are different from the sporangium. Conidia stalks called conidiophores and spores are produced are called conidia. Conidia have branches called phialides thus appear to form clump. Phialides layers are the formation and maturation of spores called sterigma [13].
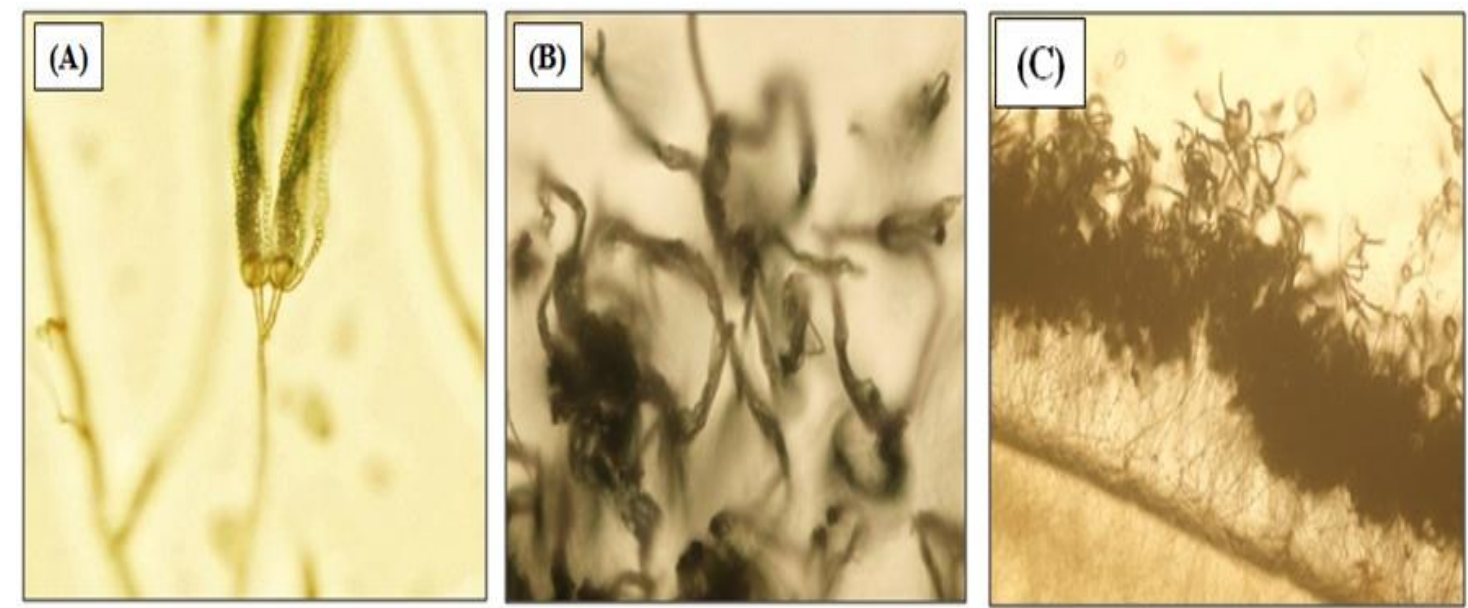

Figure 2 Pencillium sp fungi observations using a microscope using a magnification of $400 \mathrm{X}$, where (A) fungi that live single (B) fungi that live in colonies and (C) sectional fungi Penicillium sp

According to Al-Thani and Al-Meri [14], lichens are unique organisms formed by an association of green algae or cyanobacteria and fungi of the ascomycetes or basidiomycetes. There are three forms of lichens: crustose, foliose, fructicose. Therefore, the inhibition of the growth of lichens efforts attempted to kill both types of lichens constituent microorganisms. However, in this study has not found the right method for the separation of the constituent of microorganisms so this study conducted only for growth inhibition of fungal microorganisms, where the fungi obtains many food from the photosynthesis of green algae that are autotrophy, while fungi that are heterotrophic provides water, minerals and gas exchange and as a protector of algae. If one of the constituent microorganisms has been inhibited, in this study focused on the fungi, then other constituent microorganisms are algae (algae) will die because of interruption of food supplies previously provided by the fungi, so we can get an assumption that when the mould growth is inhibited, then algae will also be stunted, and lichens will eventually die.

\subsection{The effect of Cymbopogon nardus $L$ concentration to growth inhibitor activity of Lichens}

Fig. 3 show growth inhibition activities of the lemongrass essential oil Cymbopogon nardus L. to lichens with various concentrations and diameter inhibition zone are (A) blank $(0 \mathrm{~mm})(B)$ control $(0 \mathrm{~mm})(\mathrm{C})$ $1 \%(0 \mathrm{~mm})(\mathrm{D}) 5 \%(5 \mathrm{~mm})(\mathrm{E}) 10 \%(12 \mathrm{~mm})(\mathrm{F}) 15 \%(18 \mathrm{~mm})(\mathrm{G}) 20 \%(29 \mathrm{~mm})$ and $(\mathrm{H}) 25 \%(33 \mathrm{~mm})$. Fig. 3 shows the results of the antifungal tests. The lemongrass essential oil Cymbopogon nardus $L$ was found to be active against fungi in lichens. The oil ranged from 5 to $25 \%$. In general, the essential oil Cymbopogon nardus $L$ oil was more active against the species of fungi in lichens. The highest activity of the essential oil Cymbopogon nardus $L$ oil was observed against fungi with the largest inhibition zone of $33 \mathrm{~mm}$ and $25 \%$ as compared to 0 $\mathrm{mm}$ inhibition by blank (distillate water). Fig. 4 shows affectivity antifungal activity of Cymbopogon nardus $L$ with various concentrations to inhibition zone. The antifungal activity of the oil varied with its concentration and the kind of fungal species, indicating that its activity is proportional to its concentration. The highest activity of the oil was observed against fungi. 


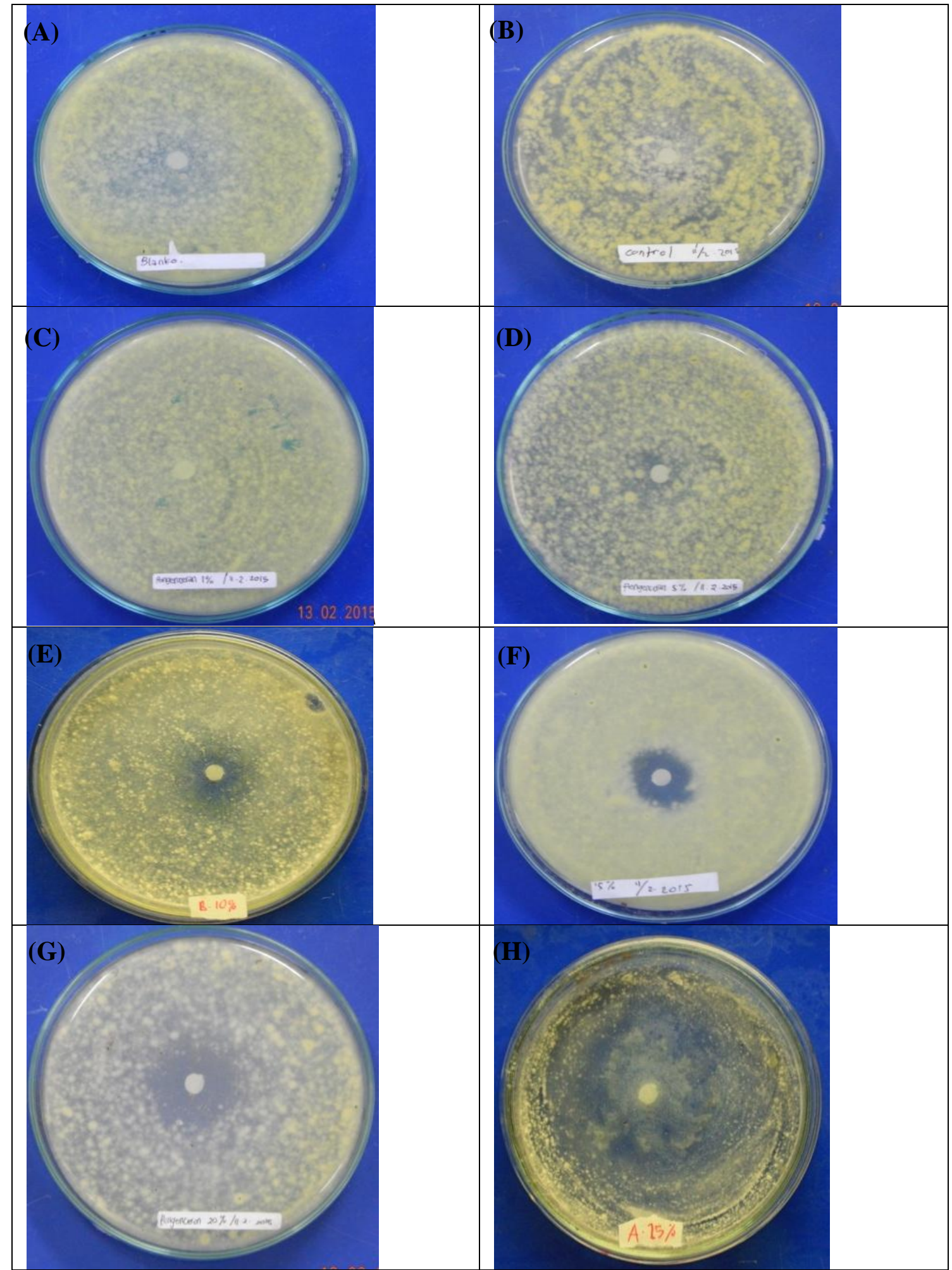

Figure 3 Growth inhibitor activities of lichens of essential oil Cymbopogon nardus $L$. with concentrations and diameter (A) blank (0 mm) (B) control (0 mm) (C) 1\% (0 mm) (D) 5\% (5mm) (E) 10\% (12mm) (F) 15\% $(18 \mathrm{~mm})(\mathrm{G}) 20 \%(29 \mathrm{~mm})$ and $(\mathrm{H}) 25 \%(33 \mathrm{~mm})$ 


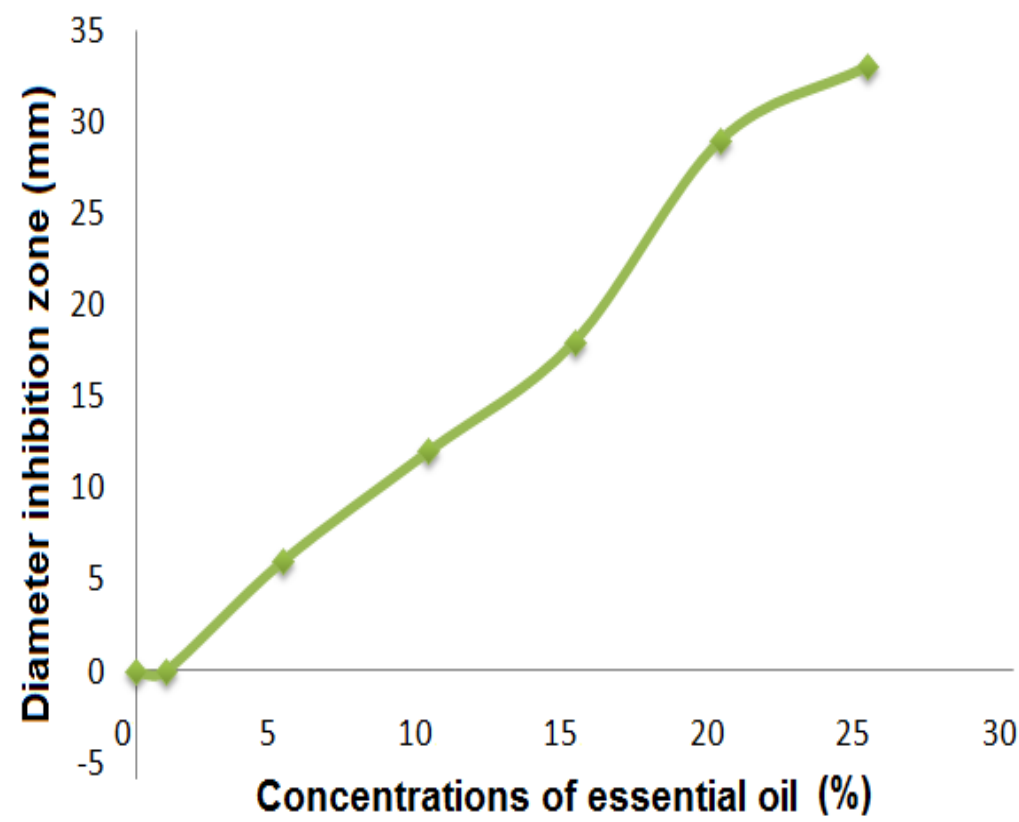

Figure 4 Graph of affectivity antifungal activity of Cymbopogon nardus $L$ with various concentrations to inhibition zone

\subsection{The effect of essential oil concentration to Growth Inhibitor of Lichens on Stone Cultural Heritage}

From observations made solvent activity test after 24 hours, it can be seen that in Fig. 5A show the activity test using acetone showed inhibition of growth in lichens is evident from the colour change of the original light green into brown colour that indicates lichens become dry. It can be concluded that acetone cannot be used as a solvent in the dilution of essential oil of essential oil Cymbopogon nardus $L$ in the study because it would interfere with the observations in the study. Fig. 5B show observation of activity test in stone heritage which $9 \%$ tween 80 in distillates water do not show any inhibition. Fig. 5C showed an inhibitory effect on lichen using essential oil Cymbopogon nardus L. While the solvent in this study used $9 \%$ tween 80 in distilled water. As a property of the oil is not soluble in water, it is necessary to lower the surface tension surfactant, therefore, be used tween 80 at a concentration of $9 \%$ in distilled water, so the formula is obtained in this research.

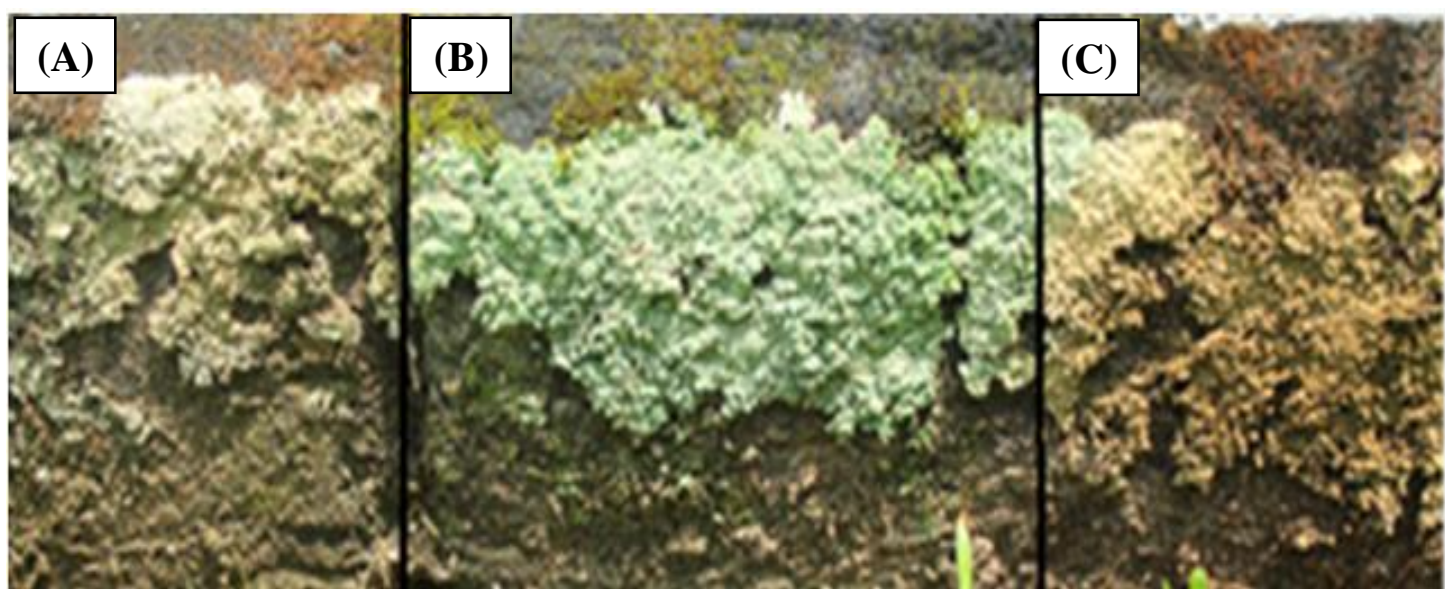

Figure 5 Results of observation of activity test in stone heritage which (A) acetone (B) $9 \%$ tween 80 in distillates water and (C) essential oil Cymbopogon nardus $L$ in $9 \%$ tween 80 in distillates water 

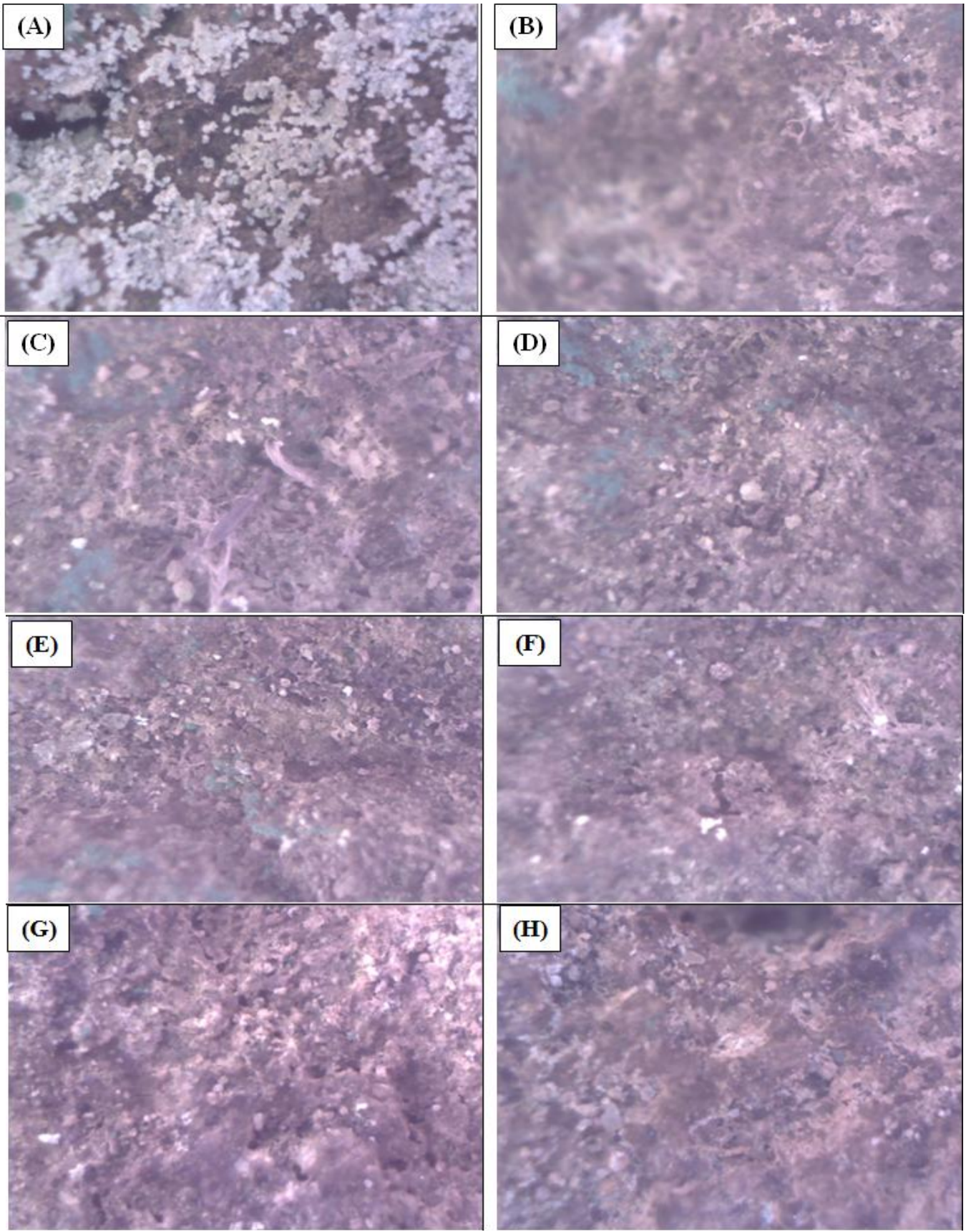

Figure 6 The effect of essential oil treatment to lichens on stone heritage using digital handy microscope, before treatment (A) after treatment with 1\% (B), 5\% (C), 10\% (D) 15\% (E), 20\% (F) 25\% (G) and 100\% (H).

Fig. 6 show the effect of essential oil treatment to lichens on stone heritage using digital handy microscope, before treatment (A) after treatment with $1 \%(B), 5 \%(C), 10 \%(D) 15 \%(E), 20 \%(F) 25 \%(G)$ and $100 \%(\mathrm{H})$. Fig. 6 show observations of the effectiveness of essential oils of citronella leaves against lichens on stone significant changes in the first 24 hours. The changes that occur are redness on the concentration of essential oils of citronella leaves 5\%,10\%,15\%,20\%, 25\% and 100\% and do not show colour changes in the concentration of $1 \%$ and a comparator. Base on observation of 168 hours, the brighter colours indicating influent essential oil of citronella against lichens on stone. Observations at 384 hours showed the collapse of Lichens on rocks caused rainwater and indicates that the essential oil of leaves of citronella lena stone effect to eradicate Lichens at a concentration of minimum 5\% due to the concentration of $1 \%$ is still visible Lichens attached to the rocks after the cleaning process. Compounds sitronela, piperitone, linalool, elemol, 1,8-cineole, limonene, geraniol, $\beta$-caryophyllene, methyl heptenone, geranyl geranyl acetate and has been known to act as an antibacterial, antifungal, antiyeast, insecticides and insect repellents in the long term [15]. 
Isolation and Application of the Lemongrass Essential Oil of Cymbopogon Nardus L.as a Growth....

\subsection{Identification Lichens using Scanning Electron Microscope (SEM)}

Fig. 7 show the result of identification of lichens on stone surface, before and after treatment essential oil Cymbopogon nardus L using scanning electron microscopy (SEM). Treatment the stone heritage sampels has been done before analyzed using SEM, the first sample is cleaned and should be free of water, and then place the sample on the sample holder with size $12 \mathrm{~mm}$ and $25 \mathrm{~mm}$, then to attach samples are needed double-side tape conductive and placed sample area will be studied at $45^{\circ}$. Furthermore, the sputtering Au metal plating with a thickness of approximately 10-30 nm. Sample has been carried out with a metal coating Au, then immediately analyzed using a SEM. Based on SEM results show the difference surface between original surface (withaout treatment) and after treatment using essential oils of lemongrass with concentration 100\%. Fig. 7 and Fig. 8 show lichens separated from the surface of stone with magnification 500 and 1000x, respectively.

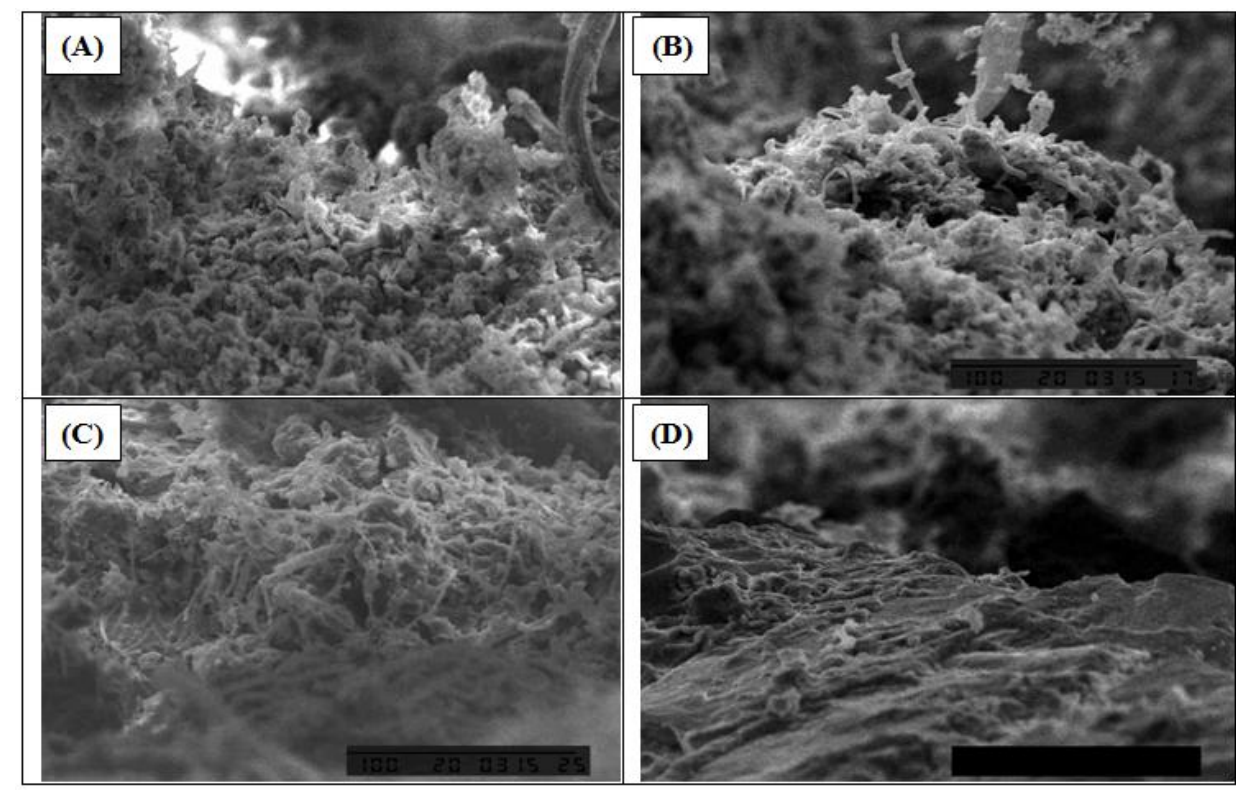

Figure 7 SEM Image from lichene before treatment (A) after treatment with essential oil Cymbopogon nardus $L$ with concentration $15 \%$ (B) $25 \%$ (C) and $100 \%$ (D) with magnification 500x
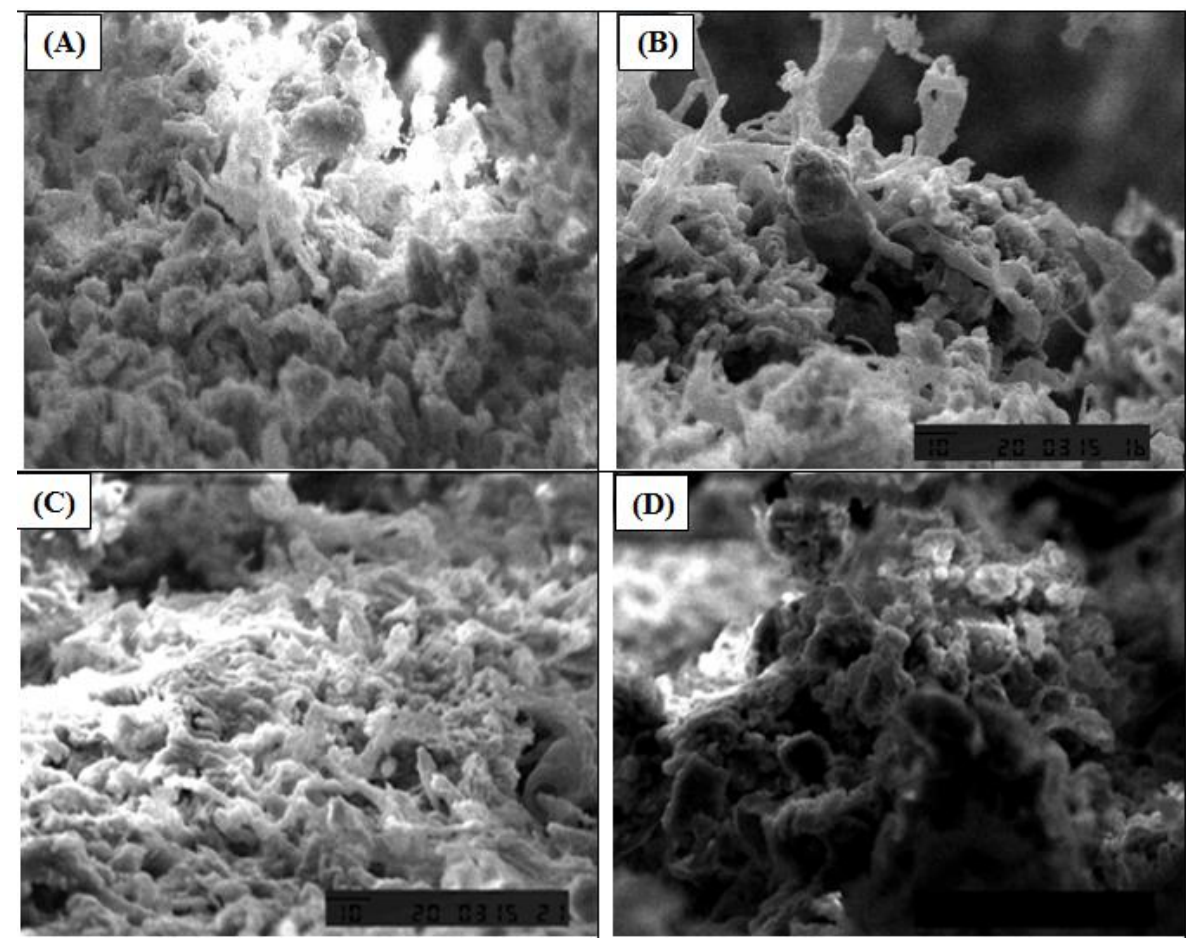

Figure 8 SEM Image from lichene before treatment (A) after treatment with essential oil Cymbopogon nardus $L$ concentration $15 \%$ (B) $25 \%$ (C) and $100 \%$ (D) with magnification $1000 x$ 


\section{Conclusion}

The essential oil of Cymbopogon nardus $L$ analyzed in this study was dominated by a high percentage of citronelle $(47.30 \%)$, beta-citronellal $(16.05 \%)$, trans-geranial $(12.98 \%)$, citronellyl acetate $(4.91 \%)$, transcaryophyllene (4.70\%) and delta-cadinene (2.15\%). The highest activity of the essential oil Cymbopogon nardus $L$ oil was observed against fungi with the largest inhibition zone of $33 \mathrm{~mm}$ as compared to $0 \mathrm{~mm}$ inhibition by blank (distillate water). Based on this research shows the concentration of the essential oil of Cymbopogon nardus increased with increasing of activity against fungi on the stone surface.

\section{Acknowledgment}

This research was supported by the Ministries of Research, Technology, and Higher Education Republic of Indonesia through "Hibah Bersaing" Research Grant 2016 for the financial support.

\section{References}

[1] P.E. Burford, M. Kierans, and M.G. Gadd, Geomycology: fungi in mineral substrata, Mycologyst, (17), 2003, 98-107.

[2] L. Chen, H.P. Blume, and L., Beyer, Weathering of rock induced by lichen colonization-a review, Catena, 39(2), 2000, 121-146.

[3] T. Matsui, E. Kawasaki, and Y. Atomi, Studies on the vibration by tourists and epiphytes on stone at the Borobudur (Conservation Science Laboratory, University of Tsukuba. Japan, 2013).

[4] L.M. Suihko, L.H. Alakomi, A.A. Gorbushina, I. Fortune, Marquardt, and M. Saarela, Characterization of Aerobic Bacterial and Fungal Microbiota on Surfaces of Historic Scottish Monuments, Syst. Appl. Microbiol., 30, 2007, 494-508.

[5] T.H. Warscheid, and J. Braams, Biodeterioration of stone: a review, Int. Biodeterioration Biodegrad., 46, $2000,343-368$.

[6] P. Adamo, and P. Violante, Weathering of rocks and neo genesis of minerals associated with lichen activity. Applied Clay Science. 16(5-6), 2000, 229-256.

[7] E. Doehne, and C.A. Price, Stone conservation, an overview of current research (2 ${ }^{\text {nd }}$ edition, The Getty Conservation Institute, Los Angeles, 2010).

[8] O. Koul, S. Walia, and G.S. Dhaliwal, Essential oils as green pesticides: potential and constrains. Biopesticides. Int. 4(1), 2008, 6384.

[9] M. Park, K. Gwak, I. Yang, W. Choi, J. Chang, E. Jeung, and I. Choi, Antifungal activities of the essential oils ini Syzygium aromaticum (L.), Merr. Et Perry and Leptospermum petersonii Bailey and their constituents against various dermatophytes. The Journal of Microbiology, 45(5), 2007, 460-465.

[10] M.S. Rakotonitainy, and B. Lavedrine, Screening for antifungal activity of essential oils and related compounds to control the biocontamination in libraries and archives storage areas, International Biodeterioration and Biodegradation, 55, $2005,141-147$.

[11] [M.B. Isman, Plant essential oils for pest and disease management. Crop Protection, 19, 2000, 603-608.

[12] K.A. Knobloch, B. Paul., H. Ilber, Weigand, and W. Weil, Antibacterial and antifungal properties of essential oil components. $J$. Ess. Oil. 1, 1989, 119-128.

[13] Purves and Sadava, Life the science of biology ( $7^{\text {th }}$ Edition. Sinauer Associates Inc. New York, 2003).

[14] R.F. Al-Thani, and H.A. Al-Meri, Study of some lichens of Qatar (Short Communication). Atl. J. Biol. 1(3), 2011, 41-46.

[15] D. Ganjewala, Cymbopogon essential oils: chemical compositions and bioactivities, International Journal of Essential Oil Therapeutics, 3, 2009, 56-65. 